\title{
Bringing the critical into doctoral supervision: What can we learn from debates about epistemic justice and the languaging of research?
}

Richard Fay, Jane Andrews, Zhuo Min Huang, and Ross White

\begin{abstract}
In this article, we discuss how, as supervisors in largely Anglophone university contexts in England, we are trying to develop supervisory practices informed by the discussions of epistemic (in)justice and the languaging of research. Having rehearsed these discussions, and considered the opportunities provided by research integrity policy formulations in our context, we conceptualise doctoral supervision critically, interculturally, and ecologically. We then report our efforts to shape the supervisory agenda so that, in the local spaces available to us, the shaping influences of the epistemic and linguistic in the wider research environment are problematised. In particular, we focus on two strands of our thinking, namely: a) the implications of epistemic hierarchies and the value of an intercultural ethic for the transknowledging at the heart of doctoral research; and $b$ ) the role of language(s) in research and the value of a translingual researcher mindset. In both strands, our thinking has moved from a more instrumental to a more critical stance regarding research, researcher thinking, and supervision. This development highlights some of the complexities involved in developing critical intercultural praxis for doctoral supervision. We conclude with recommendations - aimed at all those involved in doctoral supervision-to facilitate a critical intercultural supervisory culture.
\end{abstract}

Keywords: critical intercultural ethic; epistemic injustice; supervisory praxis; transknowledging; translingual mindset.

Received 14 December, 2020; revised version received 5 April 2021; accepted 17 August 2021. Corresponding author: Richard Fay, the University of Manchester, UK (richard.fay@manchester.ac.uk).

\section{Introduction}

When things go well, doctoral supervision can be highly rewarding and mutually fulfilling for doctoral researchers and their supervisors; but when things go awry, the experience can be disheartening or worse for all concerned (Rugg, 2020). As 
supervisors, with our own doctoral experiences receding but still valued, we seek to maximise the positive and minimise the negative supervisory possibilities in our largely Anglophone universities in England. These institutions and the cities where they are situated are culturally and linguistically diverse. So, too, are our doctoral communities. Thus, our supervisory practices are developing where the diversity of our local contexts and doctoral communities meets the institutional leanings towards English and the Anglocentricity of the increasingly global and interconnected scholarly arena in which we and our doctoral researchers have to position ourselves.

Whilst our doctoral researchers are developing their researcher identities and practices at this meeting point, we have an important role advising them about how to 'play the academic game' given that certain epistemologies and methodologies, certain voices and sources, and certain languages and academic literacies are persistently viewed in our wider research environment as more authoritative than others. At their core, doctoral supervision is pedagogic in character, involving intensely personal experiences, interpersonal relationships, and supervisor-supervisee power dynamics. These particularities are set within the local contexts and the much broader research environment. Thus, the complexities of the local play out against the backdrop of complexities of the global; and, conversely, macro-level geo-political dynamics can be felt in the micro-dynamics of supervision.

Attentive to this local-global interface, we are - to extend Holliday's (1994) thinking - engaged in a process of developing appropriate supervisory methodology. In this process, we need to try to understand how supervision may be shaped by the dynamics within and between those most immediately involved, and within and between the department(s), institution(s), funding body/ies, and other stakeholders. Supervision may be shaped, too, by the dynamics within and between the disciplinary home(s), research paradigm(s), epistemologies, and methodologies involved. Thus, doctoral supervisory cultures represent a space in which personal and interpersonal dynamics are shaped by, but can also shape, macro-level aspects of the doctoral research environment including Anglocentric global academic publishing, the epistemic and methodological canons so easily upheld by, but also challengeable through, doctoral supervision, and by the hegemonic role of English in research practice.

In this article, we begin by considering insights from the literature on epistemic (in)justice and the implications of research being languaged, and then consider how research integrity formulations might be shaping doctoral supervision. We then present the critical, intercultural, and ecological thinking which underpins our approach to developing appropriate supervisory praxis. Against this backdrop, we share our experience of actively seeking to shape the 
supervisory agenda so that, in the local spaces available to us, we can problematise some of the shaping influences in the wider ecology. In particular, as linked to the earlier discussion, we focus on the epistemic and languaging aspirations of our critical intercultural supervisory praxis. To that end, we conclude with recommendations which have, we hope, wider application.

\section{Literature review}

In this section, we explore ideas which have become increasingly prominent in our efforts to develop appropriate supervisory methodology. These ideas are drawn from different disciplines (philosophy, psychology, applied linguistics, and intercultural communication), a mixed-diet appropriate for the transdisciplinary nature of the pedagogical and dialogic practice of research supervision. In particular, this review of literature explores how researchers (such as Bhargava, 2013; Fricker, 2007) have articulated the concept of epistemic injustice and what it may mean for the knowledge landscape in which academics work. Our review uses the terms (e.g., 'Western', 'Global North') as used in the reviewed works. This strategy provides richness but also the potential for overlap or ambiguity regarding the issues being discussed. Our selection of works to review has been guided by those we feel most closely inform our thinking about a critical approach to understanding doctoral supervision in seemingly Anglophone university contexts such as ours.

\section{The knowledge landscape}

We use the metaphor of a 'landscape' of knowledge in order to signal the diversity of knowledge and sources of knowledge in cultural, geographical, and historical terms. A critical turn can be seen to be growing within the knowledge landscape and we now briefly review this territory. We begin by noting the concept of epistemic injustice, which is explored through an extensive literature and is articulated in different languages, published in different parts of the world, and can be seen to represent different experiences of, and positions with regard to, epistemic hierarchies (Fay, White, \& Huang, 2017).

Within philosophy, Fricker (2007) exposes and interrogates the injustices and ethical problems generated in everyday epistemic practices. These injustices may include experiences such as speakers not being believed because, for reasons of prejudice (named 'testimonial injustice' by Fricker), they are not perceived as credible; and speakers not having their accounts of their social experiences trusted due to a concept not being recognised in a particular society (named as 'hermeneutical injustice' by Fricker). 
Within political theory, Bhargava (2013, p. 414) states it is Western colonialism that generates such epistemic injustice by imposing changes in the content of epistemic frameworks, forcing alteration in such frameworks, and hindering an individual's capacity to sustain, retrieve, or develop their own epistemic framework. Of particular concern for him is the way in which Western concepts and categories replace or adversely affect other epistemic possibilities.

Monceri (2014) further contributes to the critical turn within the knowledge landscape by interrogating epistemic ethnocentrism and in so doing he also highlights how certain forms of knowledge, such as those produced by Western scholars, have become the norm. He concurs with Bhargava (2013) that a homogenisation of knowledge is occurring, which results in the exclusion of a rich variety of epistemological possibilities available to explore the social world.

\section{Resisting epistemic ethnocentrism}

While there is a rich literature, only briefly touched on here, identifying how a homogenisation of knowledge can be seen in certain sites, academia being one of them, there are attempts to resist or develop alternatives to this ongoing epistemic ethnocentrism. However, these attempts can generate outcomes that may not be perceived as positive, desirable or respectful, which is an area we explore next. Halvorsen (2018), for example, notes the dangers of what he terms 'epistemic expropriation', even when explicit attention is being paid to (correcting) macrolevel epistemic injustices. A consequence of the extraction or epistemic appropriation of ideas from one epistemic community and valorised in another (such as academia or a professional community) is that knowledge can become decontextualised and the social use values of the knowledge may be lost. Even with the best of intentions, power is being exercised when knowledge is taken from one context and used in another without proper attention being paid to the values of, and conditions in, the knowledge-generating context.

Further moves to resist a homogenised knowledge landscape, in which knowledge generated in the Global North is somehow preferred or prioritised, come from the works of de Sousa Santos (2015) and Hall and Tandon (2017) who use the term epistemicide. This concept refers to the process by which some knowledge systems are destroyed by others, and it, too, heightens the seriousness of the problem with maintaining a hierarchy of knowledge. Researchers may find themselves in the space where they may either contribute to or resist such epistemicide by the way they may work with local, context-specific knowledge systems in their research, or they may import ways of knowing into the context for their research which may be unfamiliar in that context.

For our specific interest in this paper, which is language and languaging as they intersect with the knowledge landscape within the academy, we note a parallel 
between de Sousa Santos' (2015) and Hall and Tandon's (2017) notion of epistemicide and linguists' concept of 'language death' or 'linguicide'. Within linguistics, Crystal (2002) discusses language death as a by-product of global languages, such as English, being adopted beyond their original contexts of use. In the linguistic anthropological tradition, Everett (2012) has used his work learning the Pirahã language while living with Pirahã people in Amazonia to reflect on the worldview a language embodies. The clear implication of such work is that every language death also reduces the richness of the knowledge landscape.

When researchers discuss 'epistemic resistance', they are confronting the ways in which power operates within the knowledge landscape. Andrews and Okpanachi (2012) direct our attention to what they call 'epistemic oppression', which has resulted in close ties between some African countries and their former colonial links being maintained, to be detrimental to the development of new, progressive, and contextualised thinking to address their concerns. Andrews and Okpanachi (2012, p. 85) present their resistance as follows: 'African people should think creatively from within and produce knowledge that is more in tune with an African context rather than depending on books, theories, and approaches from elsewhere.'

Epistemic oppression could perhaps be considered as a stage before epistemicide, referred to already in this review. Our interest in the experiences of doctoral researchers and those who guide them, such as supervisors and examiners, indicate to us that the concept of epistemic oppression is particularly important. Academics guiding and examining doctoral researchers could valuably ask themselves the extent to which their expectations may be contributing to a form of epistemic oppression within the academy. Doctoral theses are regularly examined against a criterion relating to how they make an original contribution to knowledge. The question can and should be asked here about whether the processes and practices of doctoral study serve to enforce a homogenised knowledge landscape.

We acknowledge that many of the ideas reviewed so far have their roots in earlier work to which we now turn. Using critical, feminist, and postcolonial lenses, Spivak (1994), a literary theorist, uses the term 'epistemic violence' as a way of identifying the Eurocentric, Western domination and subjugation of [former] colonial subjects and misconception of their understanding and perception of the world. For Spivak, epistemic violence erases the history of the subaltern other (1994, p. 83) and also convinces them that they do not have anything to offer to the so-called modern world; she states that 'their only option is to blindly follow the "enlightened" colonisers, learn from them, adopt their worldviews and fit into the periphery of their world as second-class citizens.' The adoption of certain worldviews, could be, we believe, what takes place within academia if different 
ways of knowing and different voices and histories are not acknowledged, foregrounded, and indeed championed.

In parallel with Spivak, Li (2016), a contemporary philosopher in China, argues that Western knowledge has a monopoly regarding whose ideas are valued and which ideas are perceived as valid in a global context. To elaborate on this critique, he uses terms including 话语垄断 [hua yu long duan / discourse/speech monopoly]; 话语霸权 [hua yu ba quan / discourse/speech hegemony]; and 西方学 术霸权 [xi fang xue shu ba quan / Western academic hegemony]. He identifies four ways in which this hegemony/monopoly harms 'Chinese philosophy'_by shading and shaping its language and discourse; blurring and confusing its original nature; disassembling its argumentation and reasoning; and hurting its spirit and values. Li (2016) considers not only the processes through which 西方学术霸权 [xi fang xue shu ba quan / Western academic hegemony] has damaged 'Chinese' knowledge, but also the outcomes of these processes, including what we translate as the conversion of content (e.g., adopting Western terms, concepts, and argumentation); the colonisation of the paradigms, systems, and approaches of meaning-making and reasoning; and the extinction of the spirit and values of Chinese traditional philosophies. Li (2016) is here problematising issues of linguistic translation and, translation of ideas from one cultural context to another, building on the notion of epistemic expropriation (Halvorsen, 2018) discussed above.

The critiques of various ways in which epistemic injustice plays out in academic work lead us to consider here, in brief, alternative approaches and new ways of generating and disseminating knowledge. Tuhiwai Smith (2012) provides detailed consideration of how research can and should be framed in a way that neither harms nor misrepresents those who are the focus for the research. This work is based on her reflexive analysis of the history of Maori people and their experiences of research. The text has the title of Decolonising Methodology and it is clear that the ideas are presented as relevant for all research, not only research with indigenous peoples.

Connell (2014) offers a new way of conceptualising social science research in what is termed 'southern theory' which promotes an approach to research that is inclusive of different voices and has a more global reach than established research approaches. To take the challenge of a decolonised methodology or a southern theory approach to research in practice, we can learn from the voices of doctoral research as incorporated into the work of Robinson-Pant and Wolf (2016). These writers explore what researching across languages and cultures might mean in practice. They discuss specific issues such as the role of an interpreter or a local research assistant in the research process, the ethics of translation and processes of knowledge construction across cultures with particular attention to power, voice, and audience for research. Robinson-Pant and Wolf (2016) recognise the language- 
and culture-related questions encountered by researchers from countries in the Global South who may be studying in research programmes located in the Global North. This work brings together the previously discussed critiques of colonial legacies in the knowledge landscape with the particularities of the doctoral supervision experience.

At play in the doctoral space are the concepts explored in this selective review of literature, namely voice, authority, knowledge, and power. We move on, in the next section, to consider how the languaging of research (Phipps \& Gonzalez, 2004) and research integrity policy (Universities UK, 2019) further shape and inform doctoral research praxis.

\section{Researching multilingually and the languaging of research}

Fay, Zhou, and Liu (2010) reflexively report on their doctoral supervisory discussions involving Chinese-speaking participants within a largely Anglophone university context of research. These doctoral researchers asked questions such as: 'Could I do my interviews in Chinese?', 'But am I allowed to do that?', and 'Should I translate or transcribe them first?' The modal verbs 'could' and 'should' convey the sense of initial incredulity (at the possibility of conducting Chinese-medium interviews whilst studying of a $\mathrm{PhD}$ to be assessed through English), their need for confirmation of this possibility, and their curiosity about an array of methodological implications of researching multilingually.

As prompted by such questions, a networking project $^{1}$ (reported in Holmes, Fay, Andrews, \& Attia, 2013, 2016) explored what was, at that time, an underdiscussed area of research practice and researcher thinking, namely the possibilities for, and complexities of, using multiple languages in research. Examination of researcher reflections on the role of language(s) in their work enabled a prototypical researcher development trajectory to be modelled involving Realisation of the possibilities and complexities (e.g., as triggered by a supervisory suggestion); Consideration of them (leading to an informed position); and Purposeful (or intentional) Action. The project case studies provided illustrations of the purposeful actions and the researcher thinking underpinning them.

More broadly, reflecting on the process of languaging in research foregrounds how people both shape and make sense of their worlds through language (Phipps \& Gonzalez, 2004, p. 167). The concept of languaging has been used by Samy Alim, Rickford, and Ball (2016) in their work on raciolinguistics in which they interrogate how language shapes and constructs race. The authors experiment with positioning and repositioning the gerund verb and the noun in these two phrases: the languaging of race and the racing of language. By so doing, they

\footnotetext{
${ }^{1}$ AHRC Research Network Project (AH/J005037/1) http://researchingmultilingually.com/
} 
are highlighting the interplay between language and the construct being discussed, in their case the construct of race.

A focus on the languaging of research invites consideration of questions including: 'What are the implications of research being languaged in globally dominant languages? and in less globally dominant languages?' The role of English in what are referred to as academic literacies exposes how the privileging of certain voices takes place in international scholarship (Curry \& Lillis, 2013; 2017). Robinson-Pant and Wolf (2016) also remind their readers that the monolingualEnglish academic environment is not the norm in communities, professions, and academic contexts around the world.

In research supervision, doctoral researchers and supervisors may benefit from developing a translingual mindset (Andrews \& Fay, 2020; Andrews, Fay, \& White, 2018a, 2018b). This would involve both doctoral researchers and supervisors finding out more about 'the linguistic features of the context of the research (i.e. focusing on the way that language(s) in that context has/have been shaped by historical, political and geographical considerations); the language preferences and habits of the participants in that research; and the way in which the linguistic is understood in the disciplinary research tradition in which the research has been designed' (Andrews \& Fay, 2020, pp. 190-191).

\section{Research integrity}

A major top-down shaping influence on doctoral supervision in the UK university sector in general, and for our institutions in particular, are the Codes of Practice regarding research culture and research integrity. These codes derive from a common source. Our institutions are members of an umbrella group (Universities UK) which seeks to provide a collective voice for approximately 140 universities across $\mathrm{UK}^{2}$ and 'maximise [their] positive impact ... for students and the public both in the UK and globally through teaching, research and scholarship'. Our doctoral supervision is shaped, in part, by the trickle down into institutional policies and practices of top-down policy specification such as the Concordat to Support Research Integrity (Universities UK, 2019) as informed by the UKRIO (2009)

\footnotetext{
${ }^{2}$ It should be noted that our institutions are located in England where English is the official language. The umbrella group includes our English universities but also those in the other constituent nations (Northern Ireland, Scotland, and Wales) where other languages (e.g., Welsh and Gaelic) are also officially recognised. The linguistic ecology in these universities thus has an extra dimension, that is, officially recognised languages other than English, of which we recognise the significance. However, because of our limited experience of these contexts, we do not directly consider these ecologies in this article.
} 
Code of practice for research: Promoting good practice and preventing misconduct.

Although the Concordat does not explicitly link epistemic injustice or languaging to research integrity, its signatories commit themselves, amongst other things, to creating a 'culture of integrity' and 'rigour' for research as conducted using 'appropriate ethical, legal and professional frameworks, obligations, and standards' following 'best practice' (Universities UK, 2019, p. 1). With this emphasis on integrity and appropriate ethical frameworks, we argue that the Concordat provides opportunities for developing supervisory methodology sensitive to the above epistemic and language issues.

The Concordat's commitments are further elaborated through a listing of the five core elements of research integrity (p. 6). The first core element is 'honesty in all aspects of research including in the presentation of research goals, intentions and findings; in reporting on research methods and procedures; in gathering data; in using and acknowledging the work of other researchers; and in conveying valid interpretations and making justifiable claims based on research findings' [emphasis added]. Regarding the italicised phrase above, in our experience, the practice of such honesty is all too often reduced to the need to guard against plagiarism and related forms of academic malpractice. Although the epistemic and languaging aspects are not explicitly present here, we would like to suggest that the use and acknowledgement of others' work would be incomplete without attention to these aspects.

The second core element is rigour 'in line with prevailing disciplinary norms and standards, ... and in communicating the results' [emphasis added]. We see it as a key objective to make disciplinary norms and standards fully attentive to the risks of epistemic injustice and consequences of the Anglocentricity of international research. This connects to the third core element, transparency and open communication and especially with the objective of 'making research findings widely available'. An argument could be made about the value of a research lingua franca, for example, the use of English for disseminating research internationally. However, there are significant consequences for researchers for whom English is an additional language (as discussed in Curry \& Lillis, 2017). Further, in part because only some articles are open access, there are inequities in who can easily access the research and whose research is easily accessed. These are compelling arguments for problematising the role of language(s) in research.

The fourth core element, care and respect for all participants in research involves, amongst other things, care and respect 'for the integrity of the research record'. We believe that such integrity should be challenging the dominant flows of ideas, challenging the use of ideas (e.g., 念 niàn/mindfulness, see Huang, Fay, \& White, 2017) in ways which decontextualise the ideas, assimilating them into the 
dominant knowledge arena; and challenging the impression that all ideas are somehow naturally articulated through English as a neutral language of international thinking. The fifth core element, 'accountability of funders, employers and researchers to collectively create a research environment in which individuals and organisations are empowered and enabled to own the research process' is a clear encouragement, we want to suggest, for researcher activism (to which we will return).

\section{Conceptualising doctoral supervision}

In this section, we present the understanding of doctoral supervision which provides the frame for our work towards appropriate supervisory methodology. This understanding has three main aspects: namely, a critical (e.g., Pennycook, 2001), intercultural (e.g., Holliday, 1999), and ecological (e.g., Stelma \& Fay, 2014) lens.

\section{A critical stance}

There are many starting points for understanding the critical including the Freirean tradition in education (e.g., Freire, 1968/1970) and the challenging of Anglocentric theorising in critical pedagogy (e.g., Darder, Mayo, \& Paraskeva, 2016). Critical applied linguistics - and, in particular, the three key elements summarised by Pennycook (2001) — has been most influential on our thinking. Pennycook suggests that critically-driven researchers need to constantly problematise the givens of their disciplines and turn 'a skeptical eye toward assumptions, ideas that have become "naturalized", notions that are no longer questioned' (p. 7). Picking up on the earlier discussion, we argue that researchers embracing the critical ethos need to question the apparent 'universality' of the dominant ideas in their field; pay close attention to the sources from which such ideas originate and are promoted; and take time to consider what ideas and sources of ideas have been normalised as less authoritative, less valued, and so on.

Pennycook also comments on the 'constant reciprocal relation between theory and practice' (p. 3), and on the interplay between reflexivity and criticality in the service of praxis. We understand praxis as 'informed, committed action' (Mattsson \& Kemmis, 2007, p. 186). In our attempts to develop appropriate supervisory methodology, we hope that all those involved in it (supervisors and their doctoral researchers) are pursuing such action in both an informed manner but also, as connecting to the third of Pennycook's elements, as committed to 'social responsibility and social transformation' (p. 6). Such responsibility and transformative action need to come to the fore in addressing epistemic injustice as 
reinforced by the linguistic hegemony of English in the global academic and research arena.

\section{A critical approach to the intercultural}

Over the last 30 years or so, intercultural communication theorising has increasingly problematised the essentialising potential of the given, naturalised, normalised, default understanding of the term 'culture', that is, culture understood in national, regional, or ethnic terms. For example, Holliday (1999), an influential thinker for our developing supervisory praxis, contrasts this given, 'large' understanding of culture with emerging 'small' cultures in which cohesive behaviour develops through the shared activities of the people undertaking them. Applying this understanding, it could be argued that each supervisory relationship is an emerging small culture (Holliday, 1999) developing through the activities undertaken by doctoral researchers, their peers, supervisors, examiners, and communities.

As applied to language classrooms, Holliday (1994, p. 29) located the emergent, classroom cultures (in which appropriate methodology might develop) within a 'host culture complex'. It is within such a complex that the small classroom culture is shaped - and, in the process, also shapes-departmental, institutional, disciplinary, practitioner, and other influences. This conceptualisation is, at its heart, an ecological one, although this is a frame which we have emphasised (see below) more than Holliday does himself.

Holliday's sense of emergent small cultures (in contrast to the more static understanding of large culture understandings) resonates with Street's (1993) understanding of culture as a verb (i.e., as an emergent process). This move towards process-oriented, verbal understandings of phenomena (which are more often viewed in more noun-like, product ways) is generative and echoes with the abovementioned languaging. It also foreshadows a key term in our thinking about supervisory praxis: transknowledging. This term appears most prominently in Heugh's $(2017,2020)$ discussion of the translanguaging role of languages in multilingual education. She argues that such education also involves 'the two-way exchange of knowledge systems' which she terms transknowledging (2020, p. 43). We have adapted the term to capture a way of understanding the epistemological landscape that challenges the wide-spread use of binaries (e.g., North/South, East/West, colonising/colonised) in the literature. Thus, we use the term transknowledging to emphasise the researcher's use of diverse epistemological resources in the process of developing or otherwise working with knowledge. This involves a shift in focus onto scholars' purposeful, creative, and flexible use of the diverse epistemological resources to which they have access (rather than focusing on the discrete epistemologies). 
Further, a critically-edged problematisation can also be applied to the given understanding of culture as a shared phenomenon. Thus, it can be seen to involve 'culturally-complex and culturally-unique' individuals (Singer, 1998) interacting with each other and with the wider environment. This move, towards an understanding of the individuals involved, challenges the givens (of e.g., 'Chinese researchers' and 'UK supervisors') but supervision nonetheless involves power hierarchies (e.g., supervisors and students; favoured epistemologies, approaches, and methodologies; and literatures by certain scholars writing in and/or accessed through privileged languages such as English). The important shaping influence of these hierarchies is something which the ecological perspective can usefully foreground.

\section{An ecological understanding of doctoral supervisory cultures}

As already mentioned, Holliday's (1994) work on appropriate methodology is broadly ecological given its concern with the bilateral shaping influences in the host culture complex with classroom culture at its centre. We understood doctoral supervision similarly, that is, with the emergent small supervisory culture developing amid the host culture complex of shaping influences. As enumerated earlier, these influences (or cultures in Holliday-an terms) include the department(s), institution(s), funding body/ies and other stakeholders; the disciplinary home(s), research paradigm(s), epistemologies, and methodologies involved; and the language(s) and epistemic landscape with its hierarchies and injustices.

Our thinking about such shaping influences draws on the idea of ecological interdependence, or mutual relationship, between an individual (or group) and their environment (Gibson, 1979; Reed, 1996). An individual's possibilities for action, or affordances, are shaped by that mutuality, and by the individual's perception of their own position and relationships to others in the world. This applies to all those involved in the supervision of a student (i.e., supervisors, doctoral researchers, reviewers, examiners). We are concerned with the agentive pursuit of research by these individuals, by their purposefulness as members of the emergent supervisory culture. Following Dennett (1987) and Malle, Moses, and Baldwin (2001), we understand such purposefulness in terms of the concept of 'intentionality'. Although there is much spontaneity in individuals' actions in the world, the ecological thinking with intentionality centrally placed assumes that the human drive to action is inherently purposeful (Papadopoulou, 2012; Tomasello et al., 2005). Thus, sooner or later, those actions in the world will be shaped by the individual's more deliberate perception of possible affordances in their environment. 
As doctoral supervisory cultures develop, they are shaped by - and are also shaping-the varied influences in the research environment. In this process, doctoral researchers and supervisors have opportunities to be intentional with, for example, their practices regarding epistemic (in)justice and the languaging of research. Their purposeful action becomes critically-edged when a reflexive aspect is added (Fay \& Stelma, 2016). Thus, critical action intentionality involves the researcher also exploring and problematising the genesis of the action possibilities, or affordances, that they perceive. In this way, the researchers account for their shaping influence on their researcher praxis, and tease out how their own ideological, political, ethical, or other intentionalities play a part in their purposeful action.

\section{Developing critical intercultural supervisory praxis}

In the above section, we viewed doctoral supervision critically (reflexively problematising the givens), interculturally (using a small cultural lens), and ecologically (attentive to what shapes supervisory cultures, but also to how such supervisory cultures can shape the wider research environment). Given these above discussions, we now reflect on our experiences of working to develop appropriate supervisory methodology, or, to put it another way, our experiences of working towards 'informed, committed action' (Mattsson \& Kemmis, 2007, p. 186) and critical intercultural supervisory praxis.

Through this development process, we have been seeking to shape the supervisory agenda so that, in the local spaces available to us, we can challenge some of the problematic shaping influences in the wider ecology. We have sought to problematise the givens and be reflexively aware of our purposeful actions within the doctoral supervisory space with a particular focus on a) the processes of transknowledging and epistemic (in)justice; and b) the languaging of research.

Our supervisory practices have developed, and continue to do so, where the cultural, linguistic, epistemic, disciplinary, and methodological diversity of our contexts meets epistemic hierarchies and the Anglocentricity of the increasingly global and interconnected scholarly arena in which all those involved - that is, ourselves, our colleagues, and our doctoral researchers - must position themselves. This meeting is mediated in our context by a policy discourse of research integrity which, although underspecified (as discussed earlier), does provide opportunities for epistemic and linguistic integrity.

For both the epistemic and linguistic strands of our thinking, the initial focus was somewhat instrumental and operational, but, through a sometimes difficult, unsettling, challenging process of further interrogation, we have begun to articulate 
a more critically-positioned, action-oriented focus. We now reflect on our separate thinking for these strands before bringing them together as a proposal for others to consider.

\section{An intercultural ethic for transknowledging}

We initially focused on the possibilities for, and complexities of, developing 'common-flows' of ideas. We were interested in the research ethics regulating scholars' purposeful, creative, and flexible use of the diverse epistemological resources to which they have access (rather than focusing on the discrete epistemologies). Our first work for this strand mapped how the concept of 念 (niàn) / mindfulness has migrated across time and space, domains and disciplines, languages and cultures (Huang, Fay, \& White, 2017). In this mapping, we identified the dominant knowledge-flows and counter-flows associated with this now widelycirculating concept and set of related practices. Problematising this case, we proposed that scholars should adopt an intercultural ethic involving:

a) acknowledgement of their debt to those using an idea before them;

b) informed, respectful, and transparent usage of ideas from different knowledge sources;

c) acceptance of the co-existence of other ways of seeing and understanding things; and

d) openness to the mutually-enriching interconnections between these different ways of thinking.

The ethic was accompanied by a caveat: '.... further and more detailed discussion is needed regarding the ways in which the conceptual migrations are shaped by the larger forces at play in knowledge development, maintenance and promotion' (2017, p. 53). In particular, the ethic needed to address the potential for epistemic injustice. Thus, the initial proposal was exactly that-initial. Significantly, it provided only a muted call to arms against epistemic injustice in the global knowledge arena. For example, we proposed that 'scholars should acknowledge their debt to those using an idea before them and be informed, respectful, and transparent about the origins of the ideas they use', a formulation avoiding the significant shaping role which epistemological power plays. To really begin critically addressing epistemic injustice we need to be asking: 'How might transknowledging be shaped by epistemic gradients arising from e.g. geo-political, gender, race, academic status and disciplinary positionings?'. In ongoing work since that initial proposal, we have proposed (Huang, Fay, \& White, 2017) a critical intercultural ethic in transknowledging. This is articulated through three principles: 
Principle 1: Recognising the role of epistemological power

Regarding the epistemological environments where doctoral transknowledging is taking place, doctoral researchers, supervisors, reviewers, and examiners all need to recognise that certain ideas, sources of ideas, and means of conveying them can accrue epistemic authority or status, occupy higher positions on the epistemic gradient, and dominate less powerful ideas, sources of ideas, and the means of conveying them.

Principle 2: Developing critical reflexivity

Recognising the role of epistemological power, we need to become critically aware of, and transparently demonstrate accountability regarding, our own epistemological practices.

Principle 3: Practising epistemic activism

Whilst engaged in transknowledging, we need to (be willing to) challenge the existing epistemic hegemonies and injustices affecting our own practices and our participation in the wider epistemological environment.

Principle 1 reasserts the need to be informed (about the existence of epistemic injustice), in ways which are reflexively, and therefore critically, framed (Principle 2 ), thereby providing the platform for epistemic activism seeking to transform the inequities of the status quo (Principle 3). We should not lose sight of the fact that researchers, especially early career researchers such as doctoral researchers, have very real concerns about employability and acceptance, and that, as sensitively supported by supervisors, they will need to make purposeful decisions about where they can be activist and where the personal-professional consequences might make this less realistic for them. Nonetheless, in proposing these principles, our suggestion was, and remains, that they may be useful for doctoral researchers and their supervisors (and more widely) who might enact them, for example, by:

- actively engaging, where appropriate and feasible, with sources in languages other than English;

- respecting the co-existence of other ways of knowing alongside their own preferences; 
- noting which literatures are present and absent in the articles, chapters, books and other works under review; and monitoring the languages, terminologies, and epistemological framings used in their disciplines.

\section{The languaging of research}

For this second strand of our thinking, we began with a desire to be more informed when advising students about the handling of data in languages other than English. Over time, this developed into a desire that students become more aware of what shapes their language choices, and, more critically, that they acknowledge and challenge the privileging of thinking articulated through some languages at the expense of thinking articulated in other languages. In sum, we wanted them to become more purposeful and, as summarised earlier, to develop a translingual mindset (Andrews, Fay, \& White, 2018a, 2018b). This mindset involves researchers actively finding out more about the linguistic possibilities and complexities.

As with the developing thinking regarding epistemic injustice, we came to realise that this articulation made only a muted call for action regarding the potential injustices arising from linguistic hierarchies within international research. We subsequently (Andrews \& Fay, 2020, p. 201) tried to strengthen this call through the following five principles:

1. Language needs to be acknowledged as central to the research process and this reaches beyond questions of translation and interpretation.

2. Issues of researcher identity, positionality, and values need to be viewed as clustering together with linguistic considerations in research projects.

3. While acknowledging linguistic repertoires within research (i.e., those of both researchers and research participants) may improve the transparency of the research process, they raise challenges for the researcher, for example, increasing the amount of data to be worked with that need acknowledgement.

4. Foregrounding language in research should involve mutual learning between doctoral researchers and supervisory teams as critical and challenging questions are addressed in the research.

5. When researchers foreground language in their research they are likely to need to challenge institutional norms and expectations as shaped by global practices, for example, in publishing.

Revisiting these principles now, we recognise that the first could be pushed further. It could specify in what ways, beyond translation and interpretation questions, the linguistic is central. Thus, it could encourage doctoral researchers and their supervisors to acknowledge that certain languages, certain voices, and certain 
epistemologies are privileged at the expense of others in dominant/prominent literatures in which doctoral researchers and supervisors immerse themselves and in which they seek to contribute. Given the developing epistemic injustice strand of our thinking, this seems like a missed opportunity.

The second principle restates the reflexivity central to the critical aspect (see the earlier discussion of Pennycook, 2001). The third principle highlights how inequitable outcomes and unethical burdens can arise within, and in between, doctoral supervisory cultures if the implications of using multiple languages are not systematically discussed and agreed decisions arrived at. The fourth principle relates to the power dynamics which can be problematic between supervisors and doctoral researchers. A critical intercultural supervisory stance needs to be attentive to these power dynamics. Finally, in the fifth principle, the transformational aspect of the critical comes to the fore, providing the impetus for challenging the implicit and explicit givens, the time-honoured customs and latest fashions, and the underdiscussed and un-/under-acknowledged implications of research being languaged.

\section{Critical intercultural supervisory praxis}

The epistemic and linguistic strands of our thinking combine in the following articulation-doctoral researchers and their supervisors need to:

1. recognise the role of epistemological power (with particular regard for how such power is languaged);

2. develop critical reflexivity (with regard to the transparency and accountability of researchers in their transknowledging and the languaging of it); and

3. practise researcher activism (with particular regard to injustices arising from epistemic and linguistic hierarchies).

\section{Concluding recommendations}

In this article, we have reported our efforts to develop a supervisory culture attentive to both to the micro-level (e.g., interpersonal dynamics) and macro-level (e.g., epistemic injustice, and linguistic hegemonies), as well as to all the shaping influences (e.g., departmental, disciplinary) between these levels. Although the critical intercultural supervisory praxis could be extended, our proposal focuses on two areas we believe are key, namely, the epistemic and the linguistic. Doctoral researchers are typically expected to embed their work in the existing literatures, to frame their research in terms of existing conceptual frameworks and theories, to link their work to the accumulating wisdom in the field(s), discipline(s), 
approach(es), and methodology/ies where, and through which, they hope to make a contribution. However, the existing landscape (of the fields, disciplines, approaches, epistemologies, and methodologies in question) has, in part, been shaped by existing epistemological gradients in, and between, the prominent literatures. These gradients privilege particular understandings, from particular sources, articulated through preferred languages. As a result, the value of those already privileged resources may be sustained and enhanced by the pressure on doctoral researchers to show due diligence with regard to these established ideas.

This is where critical reflexivity is important. Doctoral researchers and their supervisors need to be accountable for what literatures they value. They need to be able to articulate what has shaped the field such that it is these works, rather than others, that have become so prominent and so influential. Armed with a reflexivelyaware recognition of the hierarchies in the knowledge landscape in which they are working, doctoral researchers and supervisors can make informed decisions about action to guard against and address epistemic injustice and be attentive to the consequences of research being languaged.

In our experience, the process of developing critical intercultural supervisory praxis is not an easy one. Located in an institutional small culture of doctoral provision, practices are shaped by many fairly fixed influences including disciplinary preference/s; the main language(s) used in supervision; the canon of literature and theory valued by the supervisors, examiners, and other gatekeepers of the discipline, and so on-against which it can be hard to assert critical perspectives. This is why our aforementioned critical intercultural supervisory principles include researcher activism. In the absence of institutional research discourses regarding the languaging of research and equitable transknowledging, individual doctoral researchers and supervisors - and beyond them, individual reviewers and examiners - need to be emboldened and, in a spirit of researcher activism, introduce other shaping influences into the ecology of supervision. This call for researcher activism resonates with recent calls for social activism in intercultural research (e.g., Ladegaard \& Phipps, 2020). Our focus, however, is on what doctoral researchers and supervisors can, and we would argue should, be doing to intentionally shape the doctoral supervision practices within the microand macro-level research ecologies in which they are embedded.

Our journey, as reported in this article, began with something simple-that is, noting the linguistic surprise of our doctoral researchers regarding how they might use multiple languages in their studies; and noting the disappointing engagement with other epistemologies (as evident in the example of transknowledging about 念 niàn/mindfulness). Encouraged by Pennycook (2001) to be fully critical, in a spirt of 'constant scepticism' (p. 7), we have sought to develop habits of challenging and problematising the givens in our context. By so 
doing, we have been encouraged to develop two more far-reaching, more meaningful concerns, namely, the implications of languaging research through hegemonic languages, and the dangers of epistemic injustice arising from scholarly ethnocentrism.

This journey from simple observation to transformative intentionality, as mediated by the critical, is a journey we strongly recommend despite the unsettling questions and uncertainties it provokes. The formulation of a critical intercultural supervisory praxis we have now arrived at is one that we can enact in our everyday doctoral supervision. It is a formulation which we invite others to enact in their doctoral supervisory practices. For example, collectively, we can all encourage doctoral researchers to actively engage with sources in languages other than English where appropriate and feasible. Similarly, in examining and reviewing academic memberships and other engagements in the research environment, we can all reflect on the literatures both present and absent; question why this might be the case; and consider the implications of the languages, terminologies, and epistemological framings currently being used. Such actions go beyond aspirational windowdressing or use of the intercultural to launder uncritical practices. They represent realistic possibilities to shape the supervisory agenda so that, in the local spaces available to us, the shaping influences of the epistemic and linguistic in the wider research environment are also problematised. In this way, activist supervisory practices which guard against injustice can become central to developing appropriate supervisory methodology. 


\section{Author biographies}

Richard Fay is a Senior Lecturer in Education (TESOL and Intercultural Communication) in the Manchester Institute of Education at the University of Manchester where he coordinates the LANTERN doctoral community. He teaches modules on researcher education and intercultural communication through language education. He also teaches klezmer in the Music Department. His research addresses: the languaging of research (as linked to the AHRC-funded Researching Multilingually projects); epistemic injustice and a critical intercultural ethic in knowledge-work; ecological thinking and critical intentional practice; appropriate (TESOL) methodology; and intercultural musicking through klezmer ensemble performance pedagogy.

Jane Andrews is Associate Professor of Education in the Department of Education and Childhood at the University of the West of England, Bristol, UK. She has interests in teaching and research in relation to multilingualism and learning. Her recent research relates to children's experiences of being multilingual, technology and learning, out of school learning, and the languaging of research (as linked to the AHRC-funded Researching Multilingually projects).

Zhuo Min Huang is a Senior Tutor in the Manchester Institute of Education at the University of Manchester, UK. She has research interests in teaching and research in relation to intercultural/international education. Her recent work relates to: epistemic injustice and a critical intercultural ethic in knowledge-work; intercultural experience; intercultural personhood; mindfulness; and creative-arts methods.

Ross White is a Reader in Clinical Psychology in the Primary Care and Mental Health Institute of Population Health at the University of Liverpool. He has interests in Global Mental Health, the efficacy of psychological interventions for refugees in low-income countries and across the EU, and the processes involved in the linguistic/cultural adaptation of psychological therapies (as linked to the AHRC-funded Researching Multilingually projects). 


\section{References}

Andrews, J., \& Fay, R. (2020). Valuing a translingual mindset in researcher education in Anglophone higher education: Supervision perspectives. Language, Culture \& Curriculum, 33(2), 188-202.

https://doi.org/10.1080/07908318.2019.1677701

Andrews, J., Fay, R., \& White, R. (2018a). From linguistic preparation to developing a translingual orientation - possible implications of plurilingualism for researcher education. In J. Choi \& S. Ollerhead (Eds.), Plurilingualism in learning and teaching: complexities across contexts (pp. 220-233). London: Routledge.

Andrews, J., Fay, R., \& White, R. (2018b). What shapes everyday translanguaging? Insights from a global mental health research project in Northern Uganda. In G. Mazzaferro (Ed.), Translanguaging in everyday practice (pp. 257273). London: Springer.

Andrews, N., \& Okpanachi, E. (2012). Trends of epistemic oppression and academic dependency in Africa's development: The need for a new intellectual path. Journal of Pan African Studies, 5(8), 85-104. http://www.jpanafrican.org/docs/vol5no8/5.8Trends.pdf

Bhargava, R. (2013). Overcoming the epistemic injustice of colonialism. Global Policy, 4(4), 413-417. https://doi.org/10.1111/1758-5899.12093

Connell, R. (2014). Using southern theory: Decolonizing social thought in theory, research and application. Planning Theory, 13(2), 210-223. https://doi.org/10.1177/1473095213499216

Crystal, D. (2002). Language death. Cambridge: Cambridge University Press.

Curry, M. J., \& Lillis, T. (2013). A scholar's guide to getting published in English: Critical choices and practical strategies. Clevedon: Multilingual Matters.

Curry, M. J., \& Lillis, T. (Eds.). (2017). Global academic publishing: Policies, perspectives and pedagogies. Clevedon: Multilingual Matters.

Darder, A., Mayo, P., \& Paraskeva, J. (Eds.) (2016). International critical pedagogy reader. London: Routledge.

Dennett, D. (1987). The intentional stance. Cambridge, MA.: MIT Press.

de Sousa Santos, B. (2015). Epistemologies of the South: Justice against epistemicide. London: Routledge.

Everett, D. L. (2012). Language: The cultural tool. New York: Pantheon Books.

Fay, R., \& Stelma, J. (2016). Criticality, intentionality and intercultural action. In M. Dasli \& A. Diaz (Eds.), The critical turn in language and intercultural communication pedagogy: Theory, research and practice (pp. 120-146). London: Routledge. 
Fay, R., Zhou, X., \& Liu, T-H. (2010). Undertaking narrative inquiry bilingually against a monolingual backdrop. Paper presented at Narrative Matters 2010 - Exploring the narrative landscape: Issues, investigations, and interventions hosted by CIRN in Fredericton, New Brunswick, Canada, $20^{\text {th }}-22^{\text {nd }}$ May, 2010.

Freire, P. (1968/1970). Pedagogia do oprimido [The pedagogy of the oppressed (translated by M.B. Ramos)]. London: Continuum.

Fricker, M. (2007). Epistemic injustice - Power and ethics of knowing. Oxford: Oxford University Press.

Gibson, J. J. (1979). The ecological approach to visual perception. Boston, MA.: Houghton Mifflin.

Hall, B. L., \& Tandon, R. (2017). Decolonization of knowledge, epistemicide, participatory research and higher education. Research for All, 1(1), 6-19. https://doi.org/10.18546/RFA.01.1.02

Halvorsen, S. (2018). Cartographies of epistemic expropriation: Critical reflections on learning from the south. Geoforum, 95, 11-20.

https://doi.org/10.1016/j.geoforum.2018.06.018

Heugh, K. (2017). Re-placing and re-centring southern multilingualisms: A decolonial project. In C. Kerfoot \& K. Hyltenstam (Eds.), Entangled discourses: South-North orders of visibility (pp. 209-229). London: Routledge.

Heugh, K. (2020). Southern multilingualisms, translanguaging and transknowledging in inclusive and sustainable education. In P. HardingEsch \& H. Coleman (Eds.), Language and the Sustainable Development Goals: Selected proceedings of the $12^{\text {th }}$ Language and Development Conference Dakar, Senegal, 2017 (pp. 37-48). British Council. https://www.teachingenglish.org.uk/sites/teacheng/files/L024_EnglishforE ducationSystems_DakarConferenceProceedings_Web_FINAL_April2021. pdf

Holliday, A. R. (1999). Small cultures. Applied Linguistics, 20(2), 237-264. https://doi.org/10.1093/applin/20.2.237

Holliday, A. R. (1994). Appropriate methodology and social context. Cambridge: Cambridge University Press.

Holmes, P., Fay, R., Andrews, J., \& Attia, M. (2013). Researching multilingually: New theoretical and methodological directions. International Journal of Applied Linguistics, 23(3), 285-299. https://doi.org/10.1111/ijal.12038

Holmes, P., Fay, R., Andrews, J., \& Attia, M. (2016). How to research multilingually: Possibilities and complexities. In Z. Hua (Ed.), Research methods in intercultural communication: A practical guide (pp. 88-102). London: Wiley. 
Fay, R., White, R., \& Huang, Z.M. (2017). Epistemic injustice and the intercultural ethics of knowledge-work: Perspectives from Global Mental Health. Paper presented at the $17^{\text {th }}$ International Conference of the International Association for Languages and Intercultural Communication "Interrogating the 'Third Space': Negotiating meaning and performing 'culture', hosted by Edinburgh Napier University, Edinburgh, UK, $19^{\text {th }}-20^{\text {th }}$ June, 2017.

Huang, Z. M., Fay, R., \& White, R. (2017). Mindfulness and the ethics of intercultural knowledge-work. Language and Intercultural Communication, 17(1), 45-57.

https://doi.org/10.1080/14708477.2017.1261672

Ladegaard, H. J., \& Phipps, A. (2020). Intercultural research and social activism. Language and Intercultural Communication, 20(2), 67-80.

https://doi.org/10.1080/14708477.2020.1729786

Li, C. G. (2016). '以西释中'衡论 [A balanced discussion: Using the West to interpret the Chinese]. 中国哲学 [Chinese philosophy]. 4.

Malle, B. F., Moses, L. J., \& Baldwin, D. A. (Eds.) (2001). Intentions and intentionality: Foundations of social cognition. Cambridge, MA.: MIT Press.

Mattsson, M., \& Kemmis, S. (2007). Praxis-related research: Serving two masters? Pedagogy, Culture \& Society, 15(2), 185-214. https://doi.org/10.1080/14681360701403706

Monceri, F. (2014). Unmasking epistemic ethnocentrism: 'Rethinking nature' as an intercultural project. Teoria-Rivisita Di Filosofia, 34(2), 193-212.

Papadopoulou, M. (2012). The ecology of role play: Intentionality and cultural evolution. British Educational Research Journal, 38(4), 575-592.

Pennycook, A. (2001). Critical applied linguistics: A critical introduction. London: Routledge.

Phipps, A., \& Gonzalez, M. (2004). Modern languages: Learning and teaching in an intercultural field. London: Sage.

Reed, E. S. (1996). Encountering the world: Towards an ecological psychology. Oxford: Oxford University Press.

Robinson-Pant, A., \& Wolf, A. (2016). Researching across languages and cultures: A guide to doing research interculturally. London: Routledge.

Rugg, G. (2020). The unwritten rules of PhD research (3rd ed.). Maidenhead: Macgraw-Hill/Open University Press.

Samy Alim, H., Rickford, J. R., \& Ball, A. F. (2016). Raciolinguistics: How language shapes our ideas about race. Oxford: Oxford University Press.

Singer, M. H. (1998). Perception and identity in intercultural communication. Yarmouth, ME.: Intercultural Press. 
Spivak, G. C. (1994). Can the subaltern speak? In P. Williams \& L. Chrisman (Eds.), Colonial discourse and post-colonial theory: A reader (pp. 66-111). New York: Columbia University Press.

Stelma, J., \& Fay, R. (2014). Intentionality and developing researcher competence on a UK Master's course: An ecological perspective on research education. Studies in Higher Education, 39(4), 517-533. https://doi.org/10.1080/03075079.2012.709489

Street, B. V. (1993). Culture is a verb: Anthropological aspects of language and cultural process. In D. Graddol, L. Thompson, \& M. Byram (Eds.), Language and culture (pp. 23-43). Clevedon: British Association of Applied Linguistics in association with Multilingual Matters.

Tomasello, M., Carpenter, M., Call, J., Behne, T., \& Moll, H. (2005). Understanding and sharing intentions: The origins of cultural cognition. Behavioral and Brain Sciences, 28, 675-735.

Tuhiwai Smith, L. (2012). Decolonizing methodologies: Research and indigenous peoples. (2nd ed.). London: Zed Books.

UKRIO (2009). Code of practice for research: Promoting good practice and preventing misconduct. Research Integrity Office. (Last accessed on $25^{\text {th }}$ November, 2020): https://ukrio.org/wp-content/uploads/UKRIO-Code-ofPractice-for-Research.pdf

Universities UK. (2019). Concordat to support research integrity. Universities UK. (Last accessed on $10^{\text {th }}$ October, 2021:

https://www.universitiesuk.ac.uk/topics/research-andinnovation/concordat-research-integrity 